\title{
Jejunal bypass of the cardia for benign stricture: report of six cases
}

\author{
JOHN BORRIE, RICHARD W BUNTON
}

From the University of Otago and Southern Regional Thoracic Surgical Unit, Dunedin, New Zealand

ABSTRACT Jejunal bypass has restored normal swallowing in six patients with benign intractable lower oesophageal stricture resulting from (1) full-thickness reflux oesophagitis and hiatal hernia, (2) reflux associated with columnar-cell-lined oesophagus, (3) ingestion of lye, and (4) achalasia with retort-shaped oesophagus. In this technique a segment of jejunum is joined to oesophagus and stomach without resection of the stricture. The procedure is of greatest value in elderly patients with persistent dysphagia and poor respiratory reserve and when previous surgical procedures have failed to relieve the obstruction caused by a benign stricture. Though the number of such patients is small their needs are great and this procedure has provided excellent relief of symptoms during a follow-up period ranging from three to nine years.

In our unit $13 \%$ of all patients with hiatal hernia have oesophagitis requiring specific treatment. About $1 \%$ of all patients seen with hernia have a full-thickness stricture of the cardia that requires some form of foregut reconstruction. ${ }^{1}$ Complicated strictures of the lower oesophagus from lye burns and third-stage achalasia have also required surgical relief.

In the past 28 years we have used jejunum as an oesophageal substitute for these patients in three ways $^{2}$ : (1) As a Roux-en-Y oesophagojejunostomy after excision of the stricture, the stomach being completely bypassed; after the reports of Callender et al in $1961^{3}$ this procedure was abandoned. (2) As an interposed segment between oesophagus and stomach after excision of the stricture, with pyloroplasty; this procedure is excellent for those in the first and second decades of life with full-thickness stricturing at the cardia. (3) As a bypass segment between oesophagus and stomach, leaving the strictured segment in place.

This paper describes this last procedure and reports the results up to nine years after operation in six patients (table). The jejunal loop, first described by Roux in $1907^{4}$ and developed for oesophageal surgery by Allison and Da Silva, ${ }^{5}$ requires careful fashioning; the completed arrangement is shown in figure 1.

Address for reprint requests: Professor John Borrie, Department of Surgery, University of Otago, Dunedin, New Zealand.

\section{Case reports}

\section{PATIENT 1}

In February 1968 a man aged 68 reported with a one-year history of dysphagia. Barium studies showed a hiatal hernia and lower oesophageal stricture, which oesophagoscopy confirmed was $25 \mathrm{~cm}$ from the upper jaw. The stricture, $1 \mathrm{~cm}$ long, was dilated with Chevalier Jackson gum-elastic bougies of 24-40 French gauge (FG). Biopsy showed chronic reflux oesophagitis.

In March 1968 an Allison-type hiatal herniorrhaphy was performed and the stricture was again dilated to 40 FG. After this operation the hernia still remained and the oesophagus required dilatation on five further occasions (fig $2 a$ ). Because of the failure of these dilatations, a jejunal bypass was performed on 2 May 1972. The jejunal segment was placed in a retrocolic position and the upper end anastomosed obliquely to the side of the oesophagus above the stricture, the position of which was determined by palpating a wide-bore stomach tube passed down the oesophagus by the anaesthetist. The jejunogastric and jejunojejunal anastomoses were then completed and a temporary Stamm feeding gastrostomy was inserted.

After operation the patient had no further dysphagia and eight years later was fit and swallowing normally (fig $2 b$ ). He died from unrelated disease one year later. 
Clinical details of six patients having jejunal bypass for benign oesophageal stricture

\begin{tabular}{|c|c|c|c|c|c|c|}
\hline Case No & Sex & Age at operation & Type of stricture & Previous operations & $\begin{array}{l}\text { Date of } \\
\text { bypass }\end{array}$ & Follow-up \\
\hline 1 & $\mathbf{M}$ & 72 & Reflux oesophagitis & $\begin{array}{l}\text { Allison hiatal } \\
\text { herniorrhaphy March } 1968\end{array}$ & $\begin{array}{l}\text { May } \\
1972\end{array}$ & $\begin{array}{l}9 y \text { - died of unrelated } \\
\text { disease }\end{array}$ \\
\hline 2 & $\mathbf{M}$ & 55 & $\begin{array}{l}\text { Reflux oesophagitis, } \\
\text { columnar-lined } \\
\text { oesophagus }\end{array}$ & $\begin{array}{l}\text { Allison hiatal } \\
\text { herniorrhaphy June } 1969\end{array}$ & $\begin{array}{l}\text { Nov } \\
1972\end{array}$ & $9 \mathrm{y}-$ alive and well \\
\hline 3 & $\mathbf{M}$ & 81 & $\begin{array}{l}\text { Reflux oesophagitis, } \\
\text { columnar-lined } \\
\text { oesophagus }\end{array}$ & & $\begin{array}{l}\text { Sep } \\
1978\end{array}$ & $3 y-$ alive and well \\
\hline 4 & $\mathbf{M}$ & 55 & Lye stricture & $\begin{array}{l}\text { Repair of perforated } \\
\text { oesophagus Dec } 1971 \\
\text { Repair of peforated } \\
\text { oesophagus Sep } 1972\end{array}$ & $\begin{array}{l}\text { Oct } \\
1972\end{array}$ & $\begin{array}{l}4.5 y-\text { died of lung } \\
\text { carcinoma }\end{array}$ \\
\hline 5 & $\mathbf{F}$ & 72 & $\begin{array}{l}\text { Achalasia, retort } \\
\text { oesophagus }\end{array}$ & $\begin{array}{l}\text { Heller procedure and } \\
\text { Allison hiatal herniorraphy } \\
\text { Sep } 1971 \\
\text { Re-exploration of cardia } \\
\text { May } 1975\end{array}$ & $\begin{array}{l}\text { Dec } \\
1975\end{array}$ & $6 y-$ alive and well \\
\hline 6 & $\mathbf{F}$ & 74 & $\begin{array}{l}\text { Achalasia, retort } \\
\text { oesophagus }\end{array}$ & Heller procedure 1957 & $\begin{array}{l}\text { Oct } \\
1977\end{array}$ & $4 y-$ alive and well \\
\hline
\end{tabular}

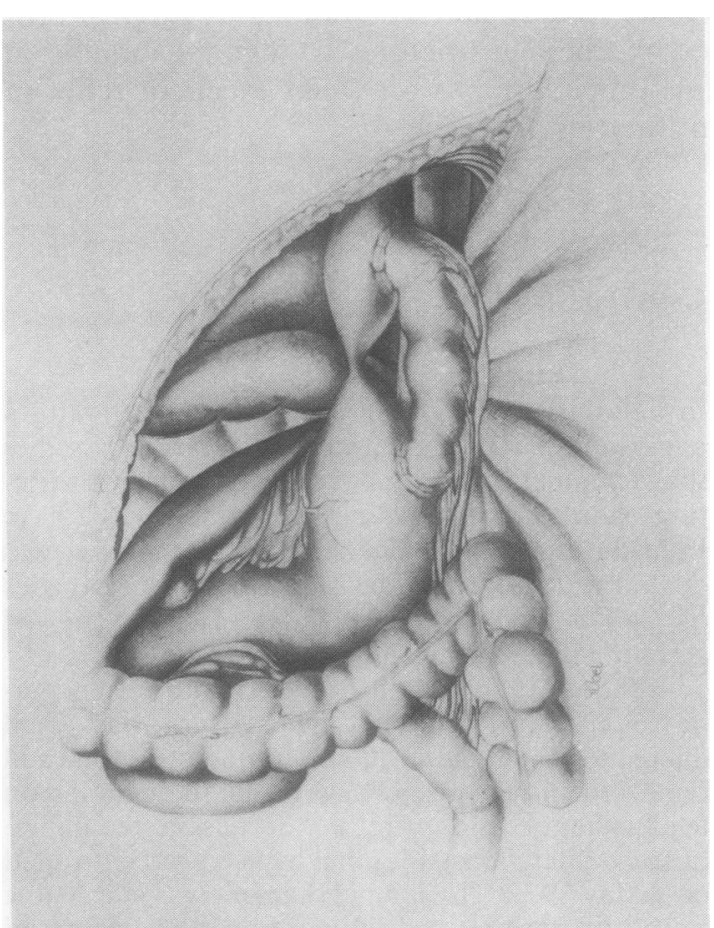

Fig 1 Diagrammatic view of the completed operation: the lower oesophageal stricture is bypassed by an isoperistaltic isolated upper jejunal segment.

\section{PATIENT 2}

A man aged 52 presented on 8 June 1969 complaining of dysphagia that had been increasing for 12 years. He had acid reflux at night when lying flat and when stooping, and occasional vomiting. Barium studies showed a large sliding hiatal hernia and a tight stricture $5 \mathrm{~cm}$ above the diaphragm.
Oesophagoscopy confirmed a stricture $34 \mathrm{~cm}$ from the upper jaw in an oesophagus lined by columnar epithelium. On 10 June 1969 hiatal herniorrhaphy was performed to reduce the hernia, and the stricture was dilated to 40 FG. In 1972, however, $\mathscr{\oplus}$ because of continued dysphagia requiring regular. dilatations and because of the patient's inability to eat anything other than semi-solid foods and liquids, further operation was advised and a jejunal bypass $\frac{\partial}{\circ}$ was performed in November 1972. Thereafter@ normal swallowing was restored and nine years later $\stackrel{\circ}{\circ}$ he remains well with normal deglutition.

\section{PATIENT 3}

A man aged 77 presented in 1973 with dysphagia that had been increasing for eight months. Oesophagoscopy showed a stricture $34 \mathrm{~cm}$ from the upper jaw. Biopsy showed ulceration in a® columnar-cell-lined oesophagus. The stricture, which was less than 10 FG in diameter, was dilated 3 . to $40 \mathrm{FG}$; but further dilatations, which were required every six months for the next five years, $३$ became increasingly difficult and hazardous. In 1978。 therefore, at the age of 81 , he had a jejunal bypass of the stricture. Three years later he continues well, eating and swallowing normally.

\section{PATIENT 4}

A man aged 55 had swallowed caustic soda accidentally in 1916. Throughout his life he had require ${ }^{\omega}$ periodic dilatations of a tight lower oesophageak stricture, especially after blockage by food. In $196 \%$ he had an episode of inhalation pneumonia. Aक lifelong smoker, he was known to have chronic bronchitis with poor lung function (FVC 2.8 litres; $\mathrm{FEV}_{1} 1$ litre; FEV $/ \mathrm{FVC}$ 30\%). In December 1971ه he again had total oesophageal occlusion. During? removal of the foreign body and dilatation of the 

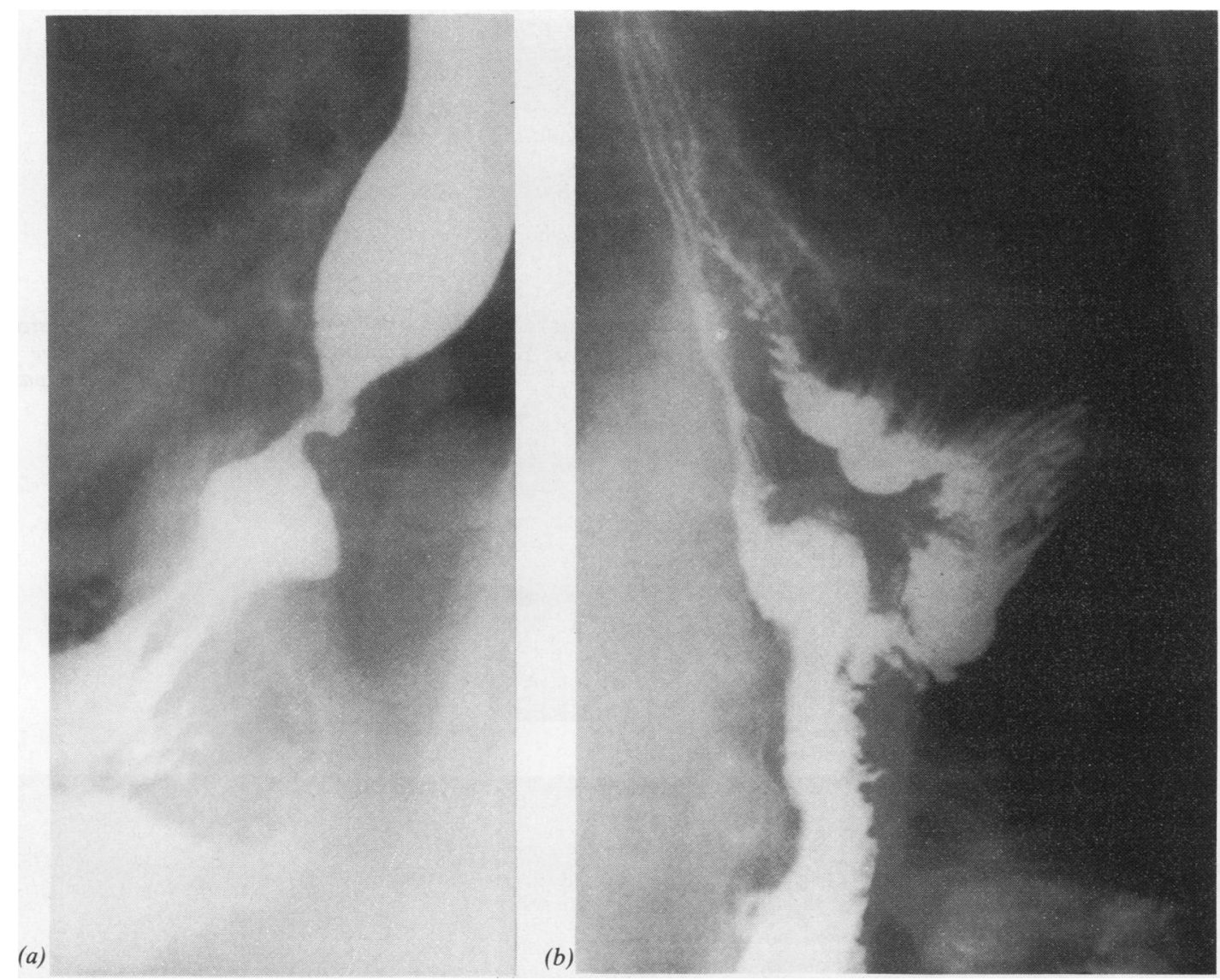

Fig 2 Patient 1: barium studies (a) in 1972 showing a hiatal hernia with stricture and ulceration and (b) in 1974 after jejunal bypass.

stricture the oesophagus was perforated. An immediate right thoracotomy was performed with oesophageal repair and retrograde dilatation of the lower oesophageal stricture. During 1972 he needed six dilatations, each more hazardous than the last (fig 3a). In September 1972 he had a second oesophageal perforation, again requiring emergency right thoracotomy and repair. Severe dysphagia continued, however, and a jejunal bypass of the stricture was performed in October 1972, with return of normal swallowing (fig 3b). He died in March 1977 from carcinoma of the lung, four and a half years after the bypass operation. Necropsy confirmed that the lower third of the oesophagus contained several fibrotic strictures and that the jejunal bypass was patent and healthy.

\section{PATIENT 5}

In 1954 a woman aged 52 complained of 30 years' dysphagia, which was found to be due to achalasia.
At that time, because of protracted treatment for bilateral detached retina, she declined any treatment for her dysphagia. Repeat barium studies in 1961 and 1970 showed increasing oesophageal dilatation and tortuosity and manometric studies showed no peristalsis.

In September 1971 a Heller's extramucosal cardiomyotomy was performed, with an Allison-type hiatal repair because of an associated enlarged oesophageal diaphragmatic hiatus. Between 1972 and 1974 the patient had continued dysphagia and the cardia was dilated with difficulty on six occasions. The lower oesophagus had now become even more retort-shaped and the dilatations were increasingly hazardous (fig 4a).

In May 1975, when the patient was 72, the cardia was again explored. Perioesophageal adhesions were divided, after which the anaesthetist could pass a Hurst mercury bougie readily down the oesophagus into the stomach. Since all seemed 

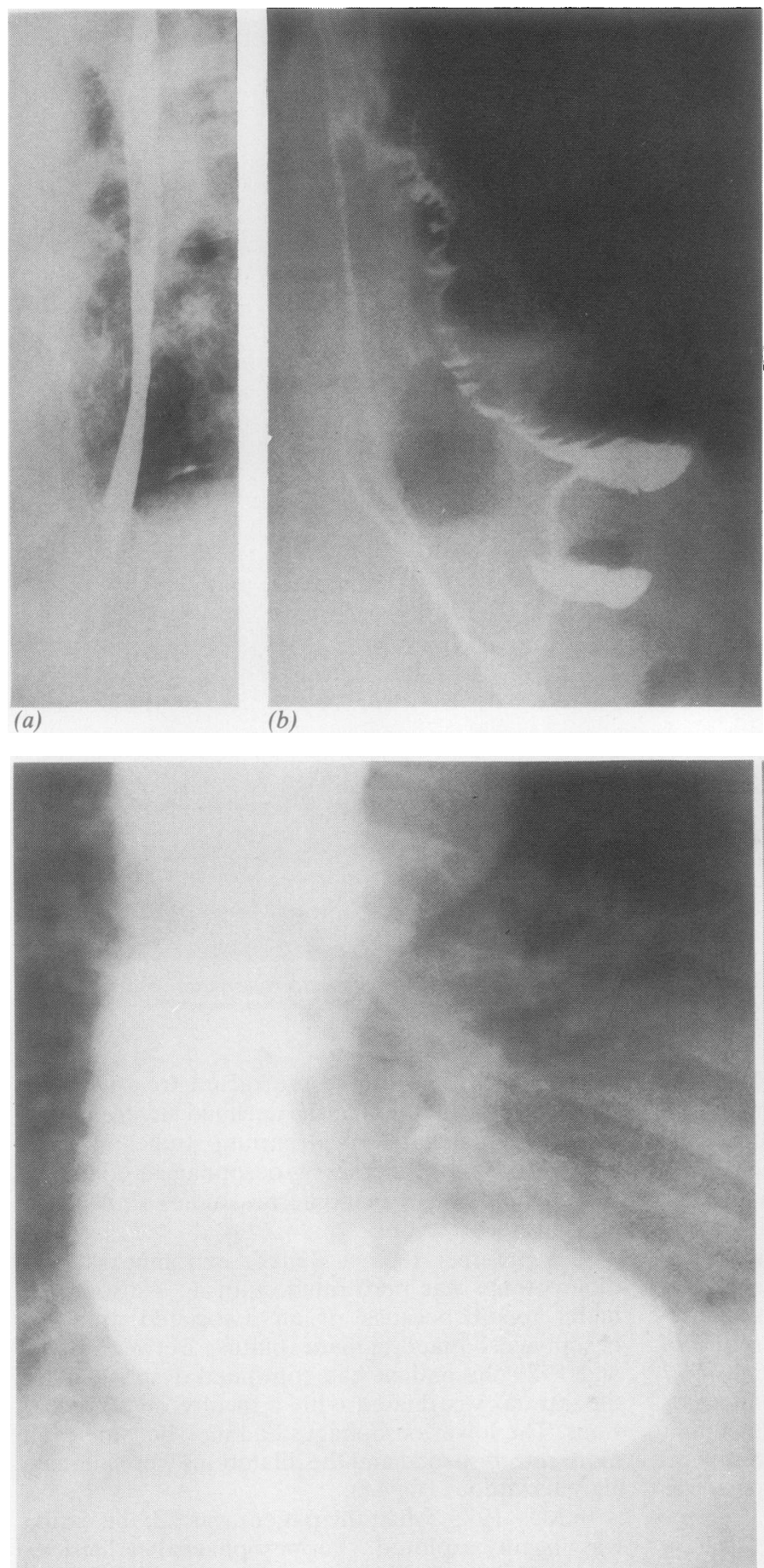

(a)

Fig 4 Patient 5: barium studies (a) in 1974 showing a dilated retort-shaped oesophagus and (b) following jejunal bypass.
Fig 3 Patient 4: barium studies (a) in March 1972 showing a lower oesophageal stricture and (b) in November 1972 after jejunal bypass.

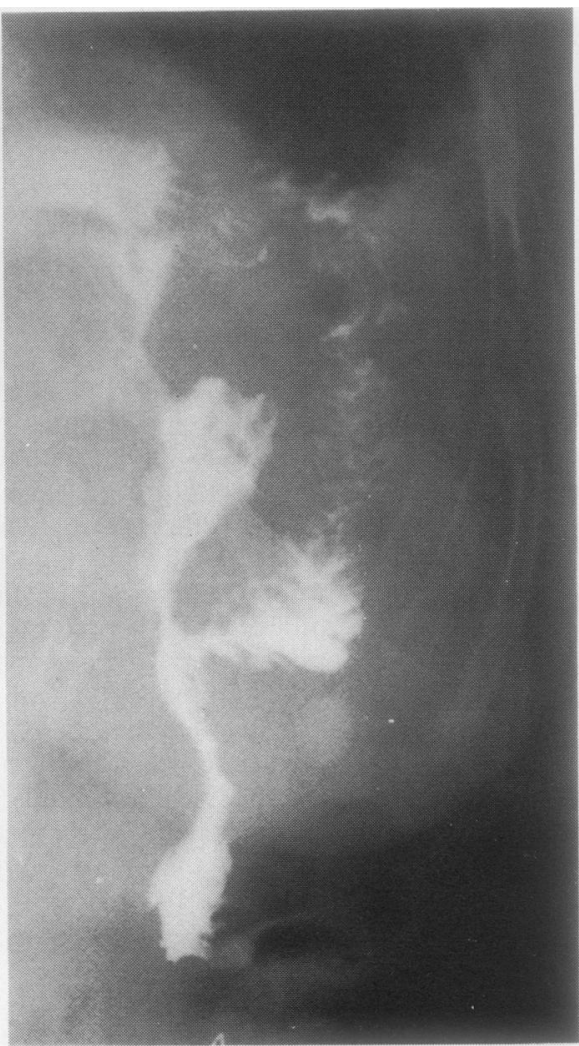

(b) 
favourable, the procedure was terminated and the chest wall closed. Within three months, however, progressive dysphagia returned and the patient's weight fell from 67 to $55 \mathrm{~kg}$. In December 1975 a jejunal bypass was performed and 13 days later the patient could eat normally (fig $4 b$ ). Six years later her swallowing remains normal.

\section{PATIENT 6}

In 1951 a woman aged 47 had a transabdominal Heller operation for achalasia, which had been present for seven years. In 1957, because of continued symptoms and increasing dilatation of her oesophagus, a transthoracic Heller operation was performed, with the cardiomyotomy extending from the inferior pulmonary vein on to the stomach for 2 $\mathrm{cm}$. Oesophagoscopy and further dilatations were required in 1964 and annually from 1966 until 1977. On the last occasion it was impossible to negotiate the strictured cardia and a jejunal bypass was performed in October 1977. Since then she has had no further dysphagia and is currently well.

\section{Discussion}

Dilatation at oesophagoscopy is the first line of treatment for benign strictures of the cardia and is successful in most cases. There remains, however, a small but important group of patients with intractable strictures in whom something more permanent is required, irrespective of the cause of the stricture. Various operations which conserve the oesophagus are available for this purpose but some of these had already been tried in five of our six cases and had failed to relieve the dysphagia. To restore normal swallowing therefore we elected to reconstruct the alimentary tract using a segment of normal gut.

This can be done either with or without resection of the stricture. The advantages of leaving the stricture in place are that the operating time is short- ened, which may be important in elderly patients or those with poor respiratory reserves, and that a difficult mediastinal dissection is avoided. This again may help to diminish the risk of postoperative complications. A theoretical disadvantage is that carcinoma may develop in the strictured area but there has been no evidence of this in our patients, who have been followed for up to nine years.

The purpose of this paper is to show that bypass without excision of the stricture not only is feasible but permits long-term satisfactory swallowing. There are alternative methods of reconstruction using stomach or a segment of colon, but in this unit we have had no experience with the former and the colonic reconstructions which have been done for various reasons have not always provided satisfactory swallowing. Radiological and oesophageal pressure studies in our unit have shown that the jejunal segment can retain active peristalsis; we have seen no evidence of gastro-oesophageal reflux or late stricture formation, and the technique has restored excellent swallowing in all six patients.

\section{References}

${ }^{1}$ Borrie J. Annual report: Southern Regional Thoracic Surgical Unit, Dunedin. Dunedin, New Zealand: Otago Medical School, 1978.

${ }^{2}$ Borrie J, Goldwater L. Columnar cell-lined oesophagus: assessment of etiology and treatment-a 22 year experience. J Thorac Cardiovasc Surg 1976;71:82534.

${ }^{3}$ Callender ST, Witts LJ, Allison PR, Gunning A. Some metabolic and haematological effects of oesophagojejunostomy with by-pass of the stomach. Gut 1961;2:150-7.

${ }^{4}$ Roux C. L'oesophago-jejuno-gastrostomose. Nouvelle operation pour retrecissement infranchissable de l'oesophage. Sem Med 1907;27:37.

5 Allison PR, Da Silva LT. The Roux loop. Br J Surg 1953;41:173-80. 
Our study investigated reversibility of $\mathrm{FEV}_{1}$ and FVC response to $200 \mu \mathrm{g}$ of inhaled salbutamol in patients with a forced expiratory ratio $<60 \%$, labelled by clinicians as asthma $(n=481)$ or chronic bronchitis/emphysema $(n=$ $356)$ and in a control group with sarcoidosis $(n=294)$. While reversibility in chronic bronchitis and sarcoidosis was normally distributed in asthma it was skewed and the asthma group could be split into two normally distributed populations (asthma group 1 mean $8 \cdot 1 \% \pm 9 \cdot 1 \%, \mathrm{n}=$ 238; asthma group 2 mean $27 \cdot 8 \% \pm 16 \%, n=247$ ). Asthma, chronic bronchitis, and emphysema all had significantly greater reversibility of $\mathrm{FEV}_{1}$ than sarcoidosis, in which it approximates to that seen in normal subjects (2.5\% $\pm 3.9 ; \mathrm{n}=75$ Watanabe et al. Am Rev Respir Dis 1974 ; 109: 550$)$. We conclude that although there is a difference in reversibility between the two populations with asthma and chronic bronchitis/emphysema there is a considerable overlap even at levels of reversibility greater than $15 \%$. The use of diagnostic labels which imply differences in reversibility is a great oversimplification which can lead to inadequate treatment.

\section{Theophylline prescribing, serum levels, and toxicity}

AA WOODCOCK, MA JOHNSON, DM GEDDES Prescriptions of slow-release theophylline preparations have risen five-fold in the last five years at the Brompton Hospital. Since March 19811913 serum theophylline assays have been performed ( $86.4 \%$ inpatients $13.6 \%$ outpatients). The number of assays per month rose three-fold following a postgraduate lecture in February 1982 (60-199 per month), but the proportion of assays in each of three groups (group A $<10 \mathrm{mg} / \mathrm{l}$; group B 10-20 mg/l; group C $>20 \mathrm{mg} / \mathrm{l}$ ) remained unchanged (A $v$ B $v$ C; $49 \% v 43 \% v$ $8 \%$ ). Theophylline prescribing was assessed retrospectively in 50 stable outpatients randomly selected from each of groups A and B and the 13 stable outpatients in group C. Oral theophylline dosage differed between the groups $(8.6 \pm 3.2 \mathrm{mg} / \mathrm{kg} /$ day $v 12.1 \pm 4.1 v 17.6 \pm 6.6 ; \mathrm{A} v \mathrm{~B} v \mathrm{C}$ (mean \pm SD)) but there was considerable overlap between the range of dosage in each group. Side effects were equal in groups $\mathrm{A}$ and $\mathrm{B}$ but greater in group $\mathrm{C}$ (for example, nausea: $26 \% v 24 \% v 62 \%$ ). Other factors related to toxic levels (group C) were abnormal liver function (36\%), diuretic therapy $(46 \%)$, and duplicate prescribing of different theophylline preparations (23\%). All group C patients but only $30 \%$ of group A patients had subsequent dosage adjustments. Serious toxicity (serum theophylline $>25 \mathrm{mg} / \mathrm{l}$ ) occurred in a total of 28 patients (six outpatients and nine inpatients on infusion, 12 inpatients on oral therapy). Three patients had fits (two died) and one was successfully resuscitated after cardiac arrest. Two further patients who were admitted to other hospitals with fits (one died) were suspected of aminophylline toxicity but theophylline assay was not available. We conclude that theophyllines are difficult to use, with considerable side effects, morbidity, and mortality. Theophylline levels are mainly used to detect toxicity in inpatients and rarely to individuals dosage in outpatients. Unsuspected toxicity in outpatients may be responsible for a considerable hidden morbidity.

\section{Cycling for patients with chronic airways obstruction}

AA WOODCOCK, MA JOHNSON We have studied cycling in seven patients with severe chronic airflow limitation disabled by breathlessness. Patients were able to cycle three to four times further than they could walk in six minutes, which is greater than the increase seen in normal subjects. Patients travelled significantly further on a lightweight tricycle (1147 metres \pm 197$)$ than on a heavy "NHS" tricycle $(833 \pm 192$ metres) or a bicycle $(1055 \pm 278$ metres) or walking ( 289 metres \pm 75 ). Patients were also less breathless after riding the lightweight tricycle (visual analogue score $6.8 \pm 2 \cdot 2)$ than the NHS tricycle $(8 \cdot 1 \pm$ $0.8)$ or the bicycle $(7.6 \pm 2.8)$ or walking $(7.9 \pm 2.7)$ despite having travelled the greatest distance. Oxygen consumption during cycling was less than half that during walking at an equivalent speed. Patients quickly adapted to the lightweight tricycle, which had the advantages of lightness and stability. Patients could adopt a good breathing posture and if they became breathless could stop to recover without dismounting. The improvement in exercise tolerance on a cycle is considerably greater than that achieved by conventional medical treatment, and we believe that a lightweight tricycle has potential in rehabilitation.

\section{Correction}

\section{Jejunal bypass of the cardia for benign stricture}

We regret that in the January issue the list of contents gave the title of the paper by J Borrie and RW Bunton incorrectly. It should be "Jejunal bypass of the cardia for benign stricture: report of six cases," as on page 31 . 